\title{
PYOCYANIN: PROCESS OPTIMIZATION AND EVALUATION OF ITS ANTIMICROBIAL ACTIVITY
}

\author{
Dange S.S. ${ }^{1}$, Gulve R.M. ${ }^{2}$, Deshmukh R.B. ${ }^{3}$, Phatake Y.B. ${ }^{1}$, Dange S.R. ${ }^{4}$ \\ ${ }^{1}$ Department of Microbiology, ADT's Shardabai Pawar Mahila College, Shardanagar, Baramati, Pune, Maharashtra, India 413115. \\ ${ }^{2}$ Department of Microbiology, N. S. S. R.'s. Mrs. K.S. Kshirsagar Alias Kaku Arts, Science and Commerce College, Beed, Maharashtra, India 431122. \\ ${ }^{3}$ Department of Botany, ADT's Shardabai Pawar Mahila College, Shardanagar, Baramati, Pune, Maharashtra, India 413115. \\ ${ }^{4}$ Department of Chemistry, Sharadchandra Pawar College, Lonand, Satara, Maharashtra, India 415521
}

Received - September 12, 2019; Revision - September 25 , 2019; Accepted - October 13, 2019

Available Online - October 15, 2019

DOI: http://dx.doi.org/10.18006/2019.7(5).494.504

\section{KEYWORDS \\ MIC \\ Phytopathogens \\ Pyocyanin \\ P. aeruginosa \\ Chromatography}

\section{* Corresponding author}

E-mail: sunitadange@gmail.com (Dange S.S.)

Peer review under responsibility of Journal of Experimental Biology and Agricultural Sciences.

Production and Hosting by Horizon Publisher India [HPI] (http://www.horizonpublisherindia.in/).

All rights reserved.

\begin{abstract}
In present study Pseudomonas aeruginosa with potential of pyocyanin pigment production was screened and its efficacy was estimated. The selected potent strain was identified up to species level by morphological, biochemical and molecular methods. The produced pigment was qualitatively and quantitatively characterized by using spectrophotometric methods. Lambda max value of the extracted pigment was found to be 320 and 520nm at alkaline and acidic conditions respectively. The conditions for growth and production of pyocyanin were optimized by classical (one parameter at a time) method in which media type and composition, physical parameters like $\mathrm{pH}$, incubation temperature and salt concentration were studied. Maximum yield was obtained from the nutrient broth containing $1 \%$ glycerol at $\mathrm{pH} 7$, Temperature $37^{\circ} \mathrm{C}$ and salt concentration $0.5 \%$. Silica gel column chromatography was effectively used for purification of extracted pyocyanin. The antimicrobial activity of the pyocyanin was evaluated against human pathogenic bacteria S. aureus, E. coli, Salmonella sp., Klebsiella sp., Proteus sp. and phytopathogenic fungi Cerratocystis caradum, Sclerotium sp., Altenaria alternatum, Aspergillus asporagus, Aspergillus niger and Penicillium sp. MIC of the pyocyanin against Staphylococcus aureus and Klebsiella sp. was found $12 \mu \mathrm{g} / \mathrm{L}$ and $8 \mu \mathrm{g} / \mathrm{L}$ respectively. The study showed that Gram negative bacteria are more sensitive to the pyocyanin than Gram positive. The pyocyanin also showed potent antifungal activity against Cerratocystis caradum, Sclerotium sp. and Altenaria alternatum.
\end{abstract}

All the articles published by Journal of Experimental Biology and Agricultural Sciences are licensed under a Creative Commons Attribution-NonCommercial 4.0 International License Based on a work at www.jebas.org.

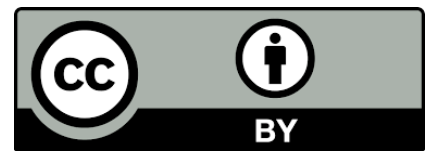




\section{Introduction}

Pseudomonas spp. are Gram-negative, aerobic bacilli with 0.5 to 0.8 $\mu \mathrm{m}$ size. It belongs to family Pseudomonadaceae with 12 other members (a member of the Gammaproteobacteria). Similar to other members of genus Pseudomonas, P. aeruginosa is ubiquitous in nature which found commonly in soil, water, plants as well as in humans body. In human being Pseudomonas spp. can cause urinary tract infections, respiratory system infections, dermatitis, soft tissue infections, bacteremia, bone and joint infections, gastrointestinal infections and a variety of systemic infections (Marathe et al., 2015). Further, recently it has been well established that $P$. aeruginosa is the principle reason behind bacteraemia in burn victims, urinary-tract infections in catheterized patients and hospital-acquired pneumonia in patients on respirators (Bodey et al., 1983; Stover et al., 2000; Usman et al., 2017 ). P. aeruginosa is the most common cause of chronic and recurrent lung infections (Cheluvappa et al., 2008; Mesquita et al., 2013).

In last few decades researchers have been attracted towards these bacteria not only because of their ability to grow in diverse environmental conditions but also to produce biologically important pigments (Usman et al., 2017). P. aeruginosa has also been reported to produce several virulence factors and blue pigment as a secondary metabolite including rhamnolipids, biofilm, biopigments, elastases, alginate, exotoxin A, exoenzymes and phospholipase C etc. (Girard \& Bloemberg, 2008; Rao et al., 2017). All the listed virulence factors are reported to be chromosomally coded (Stover, et al., 2000). These could grow very fast and shows antagonistic effect against human pathogenic bacteria as well as phytopathogens (Marathe et al., 2015).

The most notable characteristic feature of $P$. aeruginosa is the production of pyocyanin (a blue-green colored redox pigment): a water soluble blue phenazine compound (El-Fouly et al., 2015). Organisms produce these pigments in response to light and radiations (Phatake \& Dharmadhkari, 2016). Pyocyanin have various pharmacological effects such as antimicrobial, immunosuppressive, antibiofilm etc. (Venil et al., 2013; Jayaseelan et al., 2014). Antimicrobial activity of pyocyanin produced by Pseudomonas spp. was reported by Jameel et al. (2017) against Gram-positive and Gram-negative organisms. It is also used to control fungal phytopathogens (Sudhakar et al., 2013; Jameel et al., 2017). With this, pyocyanin had potent anticancer (Zhao et al., 2014) and cytotoxic activity (Hassani et al., 2012). Zhao et al. (2014) reported that it significantly inhibited HepG2 human hepatoma cells proliferation by apoptosis. Other studies also showed that pyocyanin produced by mutant strain of $P$. aeruginosa was more potent in inhibiting pelvic rhabdomyosarcoma (RD) cells (Hassani et al., 2012). Cytotoxicity assay showed that pyocyanin exhibiting toxicity against glioblastoma cells (U87MG), and it depending on the concentration of pyocyanin (Vipin et al., 2017).
In biological activity, its shows similarity with isoalloxazine, flavoprotein, flavin mononucleotide compounds (Ohfuji et al., 2004) which affects microbial communities in vicinity and communal interactions. The major skeleton of a pyocyanin is the phenazine nucleus which has the carboxyl and methyl groups on its carbon number 1 and 5 binding sites (Figure 1), respectively (Mavrodi et al., 2001). Among the natural resources, bacterial pigments are a good alternative to synthetic pigments because of their significant properties (Azmana et al., 2018).

Among various studied Pseudomonas spp., only P. aeruginosa could produces pyocyanin. Therefore, the presence of this pigment is characteristic feature of this bacterium. Compositions of media and physical conditions such as $\mathrm{pH}$, incubation temperature, period and conditions significantly affect the final yield of pyocyanin pigments (Phatake \& Dharmadhkari 2016). According to Vipin et al. (2017) overproduction of pyocyanin can be achieved by the supplementation of media with shikimic acid.

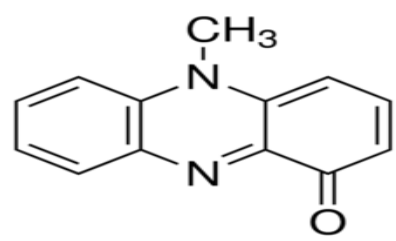

Figure 1 Structure of Pyocyanin

The aim of the present study was to isolate and screen potent and novel pyocyanin producing Pseudomonas strain from soil samples and characterization of the selected strains. Further, effect of physical factors on pyocyanin productions and its antimicrobial activity was also evaluated in current study.

\section{Materials and methods}

\subsection{Sample collection}

Pseudomonas spp. are the common inhabitants of rhizospheric soil; in current study, six soils sample were collected from different crop fields of Baramati, Pune, Maharashtra. The samples were collected from the depth of $30 \mathrm{~cm}$ by using sterile spatula. All the soil samples were collected in polyethylene bags and were brought to lab (Marathe et al., 2015).

\subsection{Enrichment, Isolation and Identification}

Five gm soil from each sample was inoculated into $100 \mathrm{ml}$ of sterile saline solution and kept on shaker at 300rpm with vigorously shaking for $1 \mathrm{hr}$. After incubation, solution was filtered through filtration assembly and $10 \mathrm{ml}$ of filtrate was inoculated in sterile nutrient broth. The inoculated broth was incubated on rotary shaker incubator at $30^{\circ} \mathrm{C} \pm 2^{\circ} \mathrm{C}$ for $24 \mathrm{hr}$. 
After incubation enriched broth was used for isolation of pigment producing bacteria. For this isolation selective sterile King's medium (peptone $20 \mathrm{~g} / \mathrm{l}$, magnesium chloride $1.4 \mathrm{~g} / \mathrm{l}$, potassium sulphate $10 \mathrm{~g} / \mathrm{l}, \mathrm{pH}$ 7) was used and isolation was carried out by four quadrant streaking method (Pedro \& Chioma, 2018).

After incubation, greenish-blue color pigmented colonies were selected and primarily identified by a colony morphology, Gram staining, biochemical characterization and by using Analytical profile index (Marathe et al., 2015). Finally the results were confirmed and bacterium was identified up-to species level by 16S rDNA technique (Maleki et al., 2010; Vora et al., 2014).

\subsection{Partial Purification of pigment}

The isolated cells were grown on nutrient broth for production of pigments, after incubation biomass were separated by centrifugation at $8000 \mathrm{rpm}$ (cooling centrifuge, Remi CRP24). The supernatant obtained was mixed with equal volume of $2: 1$ mixture of chloroform and methanol. The blue colored phase containing pigment was separated using separating funnel after vigorous shaking. The obtained pigment was concentrated by freeze drying (Mitra \& Vakilwala 2015).

\subsection{Silica gel column chromatography}

The extracted pyocyanin pigment was absorbed on small quantity of silica gel (mesh size 200-500). Silica gel absorbed extracted pigment was loaded on column $(30 \mathrm{~cm}$ length $\times 2 \mathrm{~cm}$ diameter) that had been equilibrated with $15 \%$ methanol in chloroform. Purified pyocyanin was eluted with $15 \%$ methanol in chloroform. The eluted fractions were examined by scanning UV-visible spectrophotometer.

\subsection{Qualitative characterization of pigment}

The extracted pigment was characterized by using spectrophotometric method (U.V. visible spectrophotometer, Double Beam, Elico SL210) in which the absorbance of the pigment at acidic and alkaline conditions was measured in the range of 300 to $550 \mathrm{~nm}$. For this, $0.2 \mathrm{~N} \mathrm{HCL}$ and chloroform was used as blank for acidic and alkaline conditions respectively (Mitra \& Vakilwala 2015).

\subsection{Quantitative characterization of the pyocyanin}

The extracted pyocyanin pigment was quantified by using formula given by Essar et al. (1990)

$$
\text { Pyocyanin }(\mu \mathrm{g} / \mathrm{ml})=0 \text {. D. at } 520 \mathrm{~nm} \times 17.072
$$

Where,

$$
\text { 17.072= extinction coefficient }
$$

\subsection{Optimization of pyocyanin production by classical method}

Media composition plays important role in the pigment production process. As carbon and nitrogen source present in the medium directly affect bacterial growth which ultimately affect pigment yield (Phatake \& Dharmadhikari 2016). In the present study we optimized media type and composition by using eight different types of the medium viz. nutrient broth(NB), NB+glycerol $(10 \mathrm{ml} / \mathrm{L})$, Frank's Medium-FM ( D-L alanine 10g/L, Glycerol 20ml/L, $\mathrm{K}_{2} \mathrm{HPO}_{4} 0.139 \mathrm{~g} / \mathrm{L}$, $\mathrm{MgCl}_{2} \cdot 6 \mathrm{H}_{2} \mathrm{O} 4.06 \mathrm{~g} / \mathrm{L}, \mathrm{Na}_{2} \mathrm{SO}_{4} 14.2 \mathrm{~g} / \mathrm{L}$, Ferric citrate $0.1 \mathrm{~g} / \mathrm{L}$ ), FM+ Tryptone (1\%), FM+yeast extract (1\%), FM+glucose (1\%), $\mathrm{FM}+\mathrm{KNO}_{3}(1 \%), \mathrm{FM}+(1 \%)$ bactopeptone (Ozcan \& Kaharaman, 2015). Along with this, some important physical parameters like incubation temperature, medium $\mathrm{pH}$, salt concentration, inoculum concentration, incubation time, effect of agitation etc. were also optimized (Palanichamy et al., 2011; Vipin et al., 2017). All the experiments were carried out in triplicates, standard errors were calculated and showed by error bars in bar diagrams.

\subsection{Antimicrobial activity of pyocyanin}

Antimicrobial activity of pyocyanin was tested against human pathogenic bacteria as suggested by Mamunur et al. (2014) and phytopathogenic fungi (Kim et al., 2012). Human pathogenic bacteria S. aureus, E. coli, Salmonella sp., Klebsiella sp., Proteus sp. and phytopathogenic fungi like Cerratocystis caradum, Sclerotium sp., Altenaria alternatum, Aspergillus asporagus, Aspergillus niger and Penicillium sp. was used in present study. The bacterial and fungal cultures were maintained routinely on nutrient agar and Sabouraud's agar (dextrose $40 \mathrm{~g} / \mathrm{L}$, peptone $10 \mathrm{~g} / \mathrm{L}$, agar $20 \mathrm{~g} / \mathrm{L}, \mathrm{pH}$ 5.6) plates respectively. $24 \mathrm{hr}$. old $0.1 \mathrm{ml}$ culture of each bacterium and fungus was spread on Muller Hinton agar (beef extract $2 \mathrm{~g} / \mathrm{L}$, acid hydrolysate of casein $17.5 \mathrm{~g} / \mathrm{L}$, starch $1.5 \mathrm{~g} / \mathrm{L}$, agar $17 \mathrm{~g} / \mathrm{L})$ plate by using sterile glass spreader. Sterilized Whatman Filter paper no. 1 discs were impregnated with $10 \mu 1$ pyocyanin pigment and transferred on MH agar plate and Sabouraud's agar plate for bacteria and fungi respectively. After inoculation the plates were kept in refrigerator for pre-diffusion (30min.). After this bacterial plates were transferred to incubator adjusted at $37^{\circ} \mathrm{C}$ for 24 hrs while fungal plates were incubated at room temperature. After incubation the plates were observed for zones of inhibition (Mahamuni 2015b; Zahraa et al., 2017).

\subsection{Minimum Inhibitory Concentration (MIC)}

Minimum Inhibitory Concentration (MIC) of pyocyanin was estimated against the highly sensitive bacterial strain Staphylococcus aureus and Klebsiella sp. by micro-dilution method. For this, 5 sterile test tubes were filled with $1 \mathrm{ml}$ of nutrient broth containing different concentration of pyocyanin. The concentration of the pigments was maintained in each tube at geometric progression such as $4,8,12,16$ and $20 \mu \mathrm{g} / \mathrm{ml}$. All the tubes were inoculated with $0.1 \mathrm{ml}$ of $24 \mathrm{hrs}$ old bacterial culture. Contents in all the tubes were mixed well and incubated for $24 \mathrm{hrs}$. Test tube containing lowest concentration of the pigment with no bacterial growth after incubation was considered as MIC. 


\section{Results and Discussion}

After initial enrichment, the bacterial growth was observed on the King's agar plates. The bluish green colored colonies, which are peculiar characteristic of Pseudomonas spp. were selected and screened on the basis of their pigment producing ability for further studies. Members of the genus Pseudomonas are widely distributed as free-living organisms in soils, fresh water, marine environments and in many other natural habitats (Igbinosa \& Igbinosa, 2015).

\subsection{Characterization of isolate}

The selected isolate was further identified by using biochemical characteristics and standard methods described in Bergey's manual of determinative bacteriology and analytical profile index (table 2). The results of morphological identification had been given in table 1 .

API analysis is the most reliable and quick method of identification of the microorganism. The system was developed for rapid identification of medically important pathogens in 1970 . In present study table 2 showing results of API analysis confirm that the isolated strain show similarity with Pseudomonas sp. API 20E/NE strip was used in this study. Similar test strips was used by Ponce et al. (2018) for identification of the Pseudomonas fluorescens. Organism show positive results for L-Lactate alklinization, Beta-Alanine Aralamidase pNA, D- Glucose, DMannose, L- Lactate Assimilation etc.

\subsection{S r RNA Identification (FASTA format)}

The selected isolate was identified up to genus level by $16 \mathrm{~s}$ rDNA sequencing method (Perneel et al., 2007). This method has long been used as a gold standard for determination of phylogenies of bacterial species (Weose, 1987). The bacterial DNA isolation was followed by amplification of the $16 \mathrm{~s}$ rDNA gene. The product was confirmed by gel electrophoresis. The sequence obtained was subjected to BLAST analysis which revealed that the selected isolate showed highest similarity with $P$. aeruginosa (figure 2). El-Fouly et al. (2015) also used similar approach to characterize

Table 1 Morphological characters of the isolate

\begin{tabular}{ccccccccc} 
& Size & Shape & Colour & Margin & Elevation & Opacity & Consistency \\
$\begin{array}{c}\text { Colony } \\
\text { characteristics }\end{array}$ & $5 \mathrm{~mm}$ & Circular & Bluish-green & Entire & Convex & Opaque & Smooth \\
\hline
\end{tabular}

Table 2 Results of analytical profile index analysis

\begin{tabular}{|c|c|c|c|c|c|c|c|c|c|c|c|}
\hline $\begin{array}{l}\text { Sr. } \\
\text { no. }\end{array}$ & Biochemical test & Result & $\begin{array}{l}\text { Sr. } \\
\text { no. }\end{array}$ & Biochemical test & Result & $\begin{array}{l}\text { Sr. } \\
\text { no. }\end{array}$ & Biochemical test & Result & $\begin{array}{l}\text { Sr. } \\
\text { no. }\end{array}$ & Biochemical test & Result \\
\hline 1 & $\begin{array}{l}\text { Ala-Phe-pro- } \\
\text { Arylamidase }\end{array}$ & - & 12 & Lipase & - & 23 & D- Treholase & + & 34 & D-celobiose & - \\
\hline 2 & $\mathrm{H}_{2} \mathrm{~S}$ production & - & 13 & D-Tagatose & - & 24 & $\begin{array}{l}\text { Succinate } \\
\text { Alkalinization }\end{array}$ & + & 35 & $\begin{array}{l}\text { Gama-Glutamyl } \\
\text { transferase }\end{array}$ & + \\
\hline 3 & $\begin{array}{l}\text { Beta-glucosidase } \\
\text { BGLU-26 Lysine D } \\
\text { carboxilase LDC- }\end{array}$ & - & 14 & $\begin{array}{l}\text { Alfa- } \\
\text { Glucosidase }\end{array}$ & - & 25 & $\begin{array}{l}\text { Lysine D- } \\
\text { Carboxylase }\end{array}$ & - & 36 & Beta Xylosidase & - \\
\hline 4 & $\begin{array}{l}4 \mathrm{~L}-\text { Proline- } \\
\text { Arylamidase }\end{array}$ & + & 15 & $\begin{array}{l}\text { Ornithine D- } \\
\text { Carboxylase }\end{array}$ & - & 26 & L- Arabitol & - & 37 & Urease & - \\
\hline 5 & Saccharose/ Sucrose & - & 16 & $\begin{array}{l}\text { Glu-Gly-Arg- } \\
\text { Arylamidase }\end{array}$ & - & 27 & D- Glucose & + & 38 & Malonate & - \\
\hline 6 & $\mathrm{~L}$-Lactate alklinization & + & 17 & $\begin{array}{l}\text { L-Pyrrolydonyl- } \\
\text { aryamidase }\end{array}$ & - & 28 & D-Mannose & + & 39 & Alfa Galactosidase & + \\
\hline 7 & Glycine - Arylamidase & - & 18 & $\begin{array}{l}\text { Glutiamyl } \\
\text { arylamidase } \\
\text { pNA }\end{array}$ & + & 29 & $\begin{array}{l}\text { Tyrosine } \\
\text { Arylamidase }\end{array}$ & + & 40 & Coumarate & + \\
\hline 8 & O129R resistance & + & 19 & D- Manitol & - & 30 & Citrate (Sodium) & + & 41 & $\begin{array}{l}\text { L- Lactate } \\
\text { Assimilation }\end{array}$ & + \\
\hline 9 & Adonitol & - & 20 & Palatinose & - & 31 & $\begin{array}{l}\text { Beta- N-acetyl- } \\
\text { Galactosamidase }\end{array}$ & + & 42 & Beta Galactosidase & - \\
\hline 10 & $\begin{array}{l}\text { Beta- N-acytil- } \\
\text { Glucosaminidase }\end{array}$ & - & 21 & $\begin{array}{l}\text { Fermentation / } \\
\text { Glucose }\end{array}$ & - & 32 & $\begin{array}{l}\text { L- Histidine } \\
\text { Assimilation }\end{array}$ & - & 43 & $\begin{array}{l}\text { Keto }-\mathrm{D} \\
\text { Gluconate }\end{array}$ & - \\
\hline 11 & D- Maltose & - & 22 & $\begin{array}{l}\text { Beta Alanine } \\
\text { Aralamidase } \\
\text { pNA }\end{array}$ & + & 33 & Ellaman & - & 44 & $\begin{array}{l}\text { Beta - } \\
\text { Gluconoridase }\end{array}$ & - \\
\hline
\end{tabular}

Journal of Experimental Biology and Agricultural Sciences

http://www.jebas.org 
AGAGTTTGATCATGGCTCAGATTGAACGCTGGCGGCAGGCCTAACACATGCAAGTCGAGCGGATGAAGGGAGCTTGCTCCTGGATTCAGCGGCGGAC GGGTGAGTAATGCCTAGGAATCTGCCTGGTAGTGGGGGATAACGTCCGGAAACGGGCGCTAATACCGCATACGTCCTGAGGGAGAAAGTGGGGGATC TTCGGACCTCACGCTATCAGATGAGCCTAGGTCGGATTAGCTAGTTGGTGGGGTAAAGGCCTACCAAGGCGACGATCCGTAACTGGTCTGAGAGGAT GATCAGTCACACTGGAACTGAGACACGGTCCAGACTCCTACGGGAGGCAGCAGTGGGGAATATTGGACAATGGGCGAAAGCCTGATCCAGCCATGCC GCGTGTGTGAAGAAGGTCTTCGGATTGTAAAGCACTTTAAGTTGGGAGGAAGGGCAGTAAGTTAATACCTTGCTGTTTTGACGTTACCAACAGAAT AAGCACCGGCTAACTTCGTGCCAGCAGCCGCGGTAATACGAAGGGTGCAAGCGTTAATCGGAATTACTGGGCGTAAAGCGCGCGTAGGTGGTTCAGC AAGTTGGATGTGAAATCCCCGGGCTCAACCTGGGAACTGCATCCAAAACTACTGAGCTAGAGTACGGTAGAGGGTGGTGGAATTTCCTGTGTAGCGG TGAAATGCGTAGATATAGGAAGGAACACCAGTGGCGAAGGCGACCACCTGGACTGATACTGACACTGAGGTGCGAAAGCGTGGGGAGCAAACAGGA TTAGATACCCTGGTAGTCCACGCCGTAAACGATGTCGACTAGCCGTTGGGATCCTTGAGATCTTAGTGGCGCAGCTAACGCGATAAGTCGACCGCCT GGGGAGTACGGCCGCAAGGTTAAAACTCAAATGAATTGACGGGGGCCCGCACAAGCGGTGGAGCATGTGGTTTAATTCGAAGCAACGCGAAGAACCT TACCTGGCCTTGACATGCTGAGAACTTTCCAGAGATGGATTGGTGCCTTCGGGAACTCAGACACAGGTGCTGCATGGCTGTCGTCAGCTCGTGTCGT GAGATGTTGGGTTAAGTCCCGTAACGAGCGCAACCCTTGTCCTTAGTTACCAGCACCTCGGGTGGGCACTCTAAGGAGACTGCCGGTGACAAACCGG AGGAAGGTGGGGATGACGTCAAGTCATCATGGCCCTTACGGCCAGGGCTACACACGTGCTACAATGGTCGGTACAAAGGGTTGCCAAGCCGCGAGGT GGAGCTAATCCCATAAAACCGATCGTAGTCCGGATCGCAGTCTGCAACTCGACTGCGTGAAGTCGGAATCGCTAGTAATCGTGAATCAGAATGTCAC GGTGAATACGTTCCCGGGCCTTGTACACACCGCCCGTCACACCATGGGAGTGGGTTGCTCCAGAAGTAGCTAGTCTAACCGCAAGGGGGACGGTTACC ACGGAGTGATTCATGACT GGGGTGAAGTCGTA

Figure 2 16s rDNA sequence of selected isolate

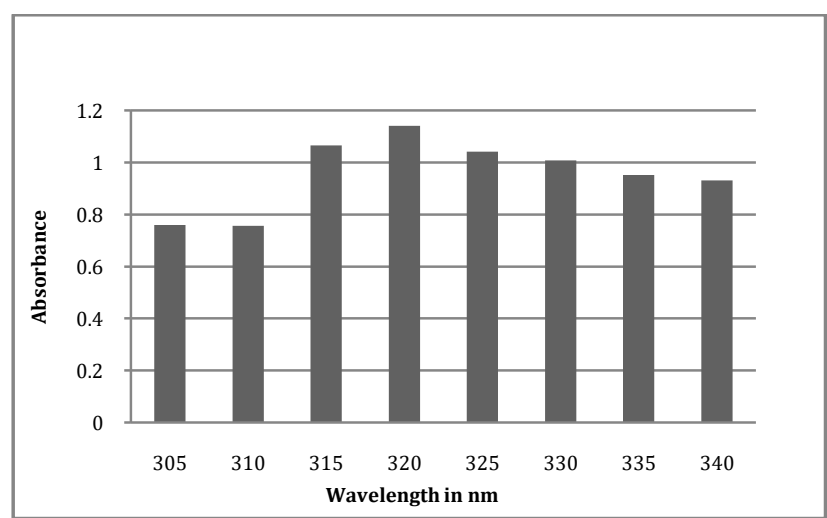

Alkaline condition

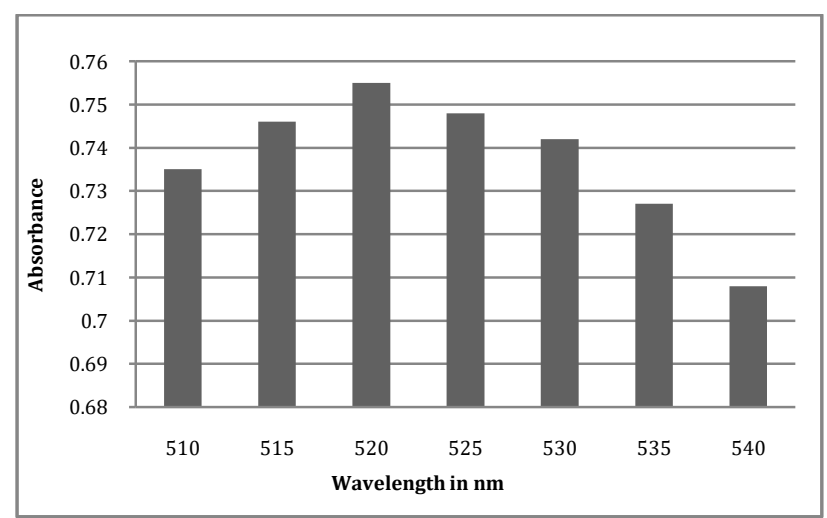

Acidic condition

Figure 3 Determination of Lambda max

Table 3 Blast report of the isolate

\begin{tabular}{|c|c|c|c|c|c|c|}
\hline $\begin{array}{c}\text { Sr. } \\
\text { No. }\end{array}$ & \multicolumn{2}{c}{ Closest Neighbor } & \multicolumn{2}{c}{ Strain } & Citation & \multicolumn{2}{c|}{ Accession No. } & $\begin{array}{c}\text { Pair-wise } \\
\text { Similarity (\%) }\end{array}$ & Diff/Total nt \\
\hline 1. & $\begin{array}{c}\text { Pseudomonas } \\
\text { aeruginosa }\end{array}$ & JCM 5962(T) & $\begin{array}{c}\text { (Schroeter 1872) } \\
\text { Migula 1900 }\end{array}$ & BAMA01000316 & 100 & $0 / 1486$ \\
\hline
\end{tabular}

organism (P. fluorescens) isolated from soil sample.

Table 3 showing blast hit results, the isolate showed $100 \%$ similarity with $P$. aeruginosa JCM 5962. The obtained results confirmed that both subject and query sequence show zero difference in total 1486 nucleotide compared.

\subsection{Determination of $\lambda$ max}

$\lambda$ max value of pyocyanin at alkaline and acidic condition were determined by spectrophotometric studies. Pyocyanin absorbed maximum at wave length $320 \mathrm{~nm}$ at alkaline and $520 \mathrm{~nm}$ at acidic condition. Further increase or decrease in the wavelength showed decrease in the final absorbance. El-Fouly et al. (2015) extract yocyanin by standard methods, purified by column chromatography, characterized by UV-Vis absorption spectroscopy and reported absorption maxima $316 \mathrm{~nm}$ in alkaline condition and $518 \mathrm{~nm}$ in acidic conditions (Figure 3 ). The findings are in agreement with previous reports of Ohfuji et al. (2004).

Journal of Experimental Biology and Agricultural Sciences http://www.jebas.org 


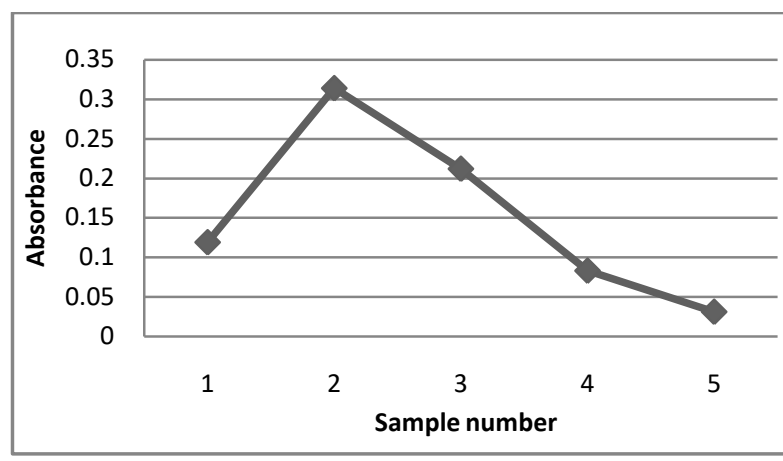

Figure 4 Different pigment samples purified by column chromatography

\subsection{Silica gel column chromatography}

The silica gel (mesh size 200-500) was used for purification of the extracted pigment. Like most of the low molecular weight pigments, pyocyanin appeared in yellow and blue bands. Different fractions of elutes were collected separately and blue fraction was used for further analysis. The fraction showed presence of pigment pyocyanin. The figure 4 showing absorbance of the different fractions at fixed wavelength. Blue colour fraction (2) showed maximum absorbance indicating presence of high concentration of pyocyanin in it. As time of elution increases value of absorbance decreases near linearly (fraction 3 onward). The results indicate that silica gel chromatography can be readily used in purification of pyocyanin.

\subsection{Optimization of pyocyanin production}

In the present study pyocyanin production was optimized by using classical approach. Among the eight different types of the medium selected, NB+ glycerol have given highest yield this was followed by $\mathrm{NB}, \mathrm{FM}+$ tryptone and $\mathrm{FM}+$ bactopeptone. FM medium alone and along with yeast extract and bactopeptone showed complete inhibitory effect of pyocyanin (Figure 5a). According to Bhatini et al. (2013) bacterial pigment production process can be effectively optimized by using classical approach. Current study also suggested that compared to synthetic medium a natural medium supports the growth of the bacteria and at the same time prove efficient in activating high levels of pigment production.

To check the effect of different incubation temperature, medium inoculated with test organism were incubated at 21, 24, 27, 30 up to $42^{\circ} \mathrm{C}$. Result of study revealed that maximum pyocyanin production occurred at $27^{\circ} \mathrm{C}$ (Figure 5b). Rest of the tested temperature was not found effective and did not have any significant effect on the final yield of the pyocyanin. Like, temperature, $\mathrm{pH}$ of the medium also plays important role in the pyocyanin production (Figure $5 \mathrm{c}$ ). In current study maximum pyocyanin was reported in the medium having natural $\mathrm{pH}$ (7). While more acidic or alkaline condition had inhibitory effect on pyocyanin production.

Pyocyanin is a secondary metabolite which produced in stationary (tropho) phase of bacterial growth. So time of incubation played a very important role in pyocyanin production process. Among the tested times, $P$. aeruginosa gives maximum yield when it incubated for $72 \mathrm{hrs}$, further increase in the incubation time do not show improvement in the yield of pyocyanin (Figure 5d).

In current study effect of different $\mathrm{NaCl}$ concentration on the growth of $P$. aeruginosa and pigment production were studied. $\mathrm{NaCl}$ involved in the regulation of osmotic balance of the cell. Results of study suggested that highest pigment synthesis was occurred when media is supplemented with $4 \% \mathrm{NaCl}$ and this was followed by rest treatments (Figure 5e).

The initial cell density affects the oxygen mass transfer rate which directly alters the final yield of the product. In present study sterile production media was inoculated with different concentration of the inoculum viz. 1, 2, 5 and 10\%. Maximum pyocyanin producted was reported when media was inoculated by $1 \%$ inoculums, this was followed by 2, 5 and $10 \%$ inoculums concentration (Figure 5f). From the result of study, it can be conclude that increase in initial cell concentration have negative effect on the pigment production.

\subsection{Antimicrobial activity of pyocyanin against human pathogens}

The antibacterial effect of the purified pyocyanin was determined against human GIT pathogens S. aureus, E. coli, Salmonella sp., Klebsiella sp. and Proteus sp. by agar disc diffusion method. Notable effect was observed against all the pathogens (Figure 6 -9). All the tested Gram negative pathogens showed sensitivity to pyocyanin. The pigment showed highest activity against Salmonella sp. $(25 \mathrm{~mm})$.

Results of current study are in conformity to the findings of Zahraa et al. (2017) those who suggested that pyaocyanin has antimicrobial activity against various human pathogenic bacteria such as Shigella sp., Staphyllococcus aureus and Staphyllococcus epidermedis and pathogenic fungi and yeast; Aspergillus niger, Penicillium spp., Rhizopus spp., Trichophyton mentagrophyte, Rhodotorula spp., Alternaria alternate, Trichophyton rubrum and Candida spp.

Similarly Mohammed \& Almahde (2017) also reports inhibitory effect of pyocyanin against urinary tract pathogens $S$. aureus, $S$. saprophyticus, S. epidermidis, E. coli and C. frundii. Further, it was reported that clinical strains of $K$. pneumoniae and $P$. aeruginosa were resistant to pyocyanin while all Gram-positive bacteria and $C$. albicans could be significantly inhibited by pyocyanin treatment (Pachori et al., 2019). 


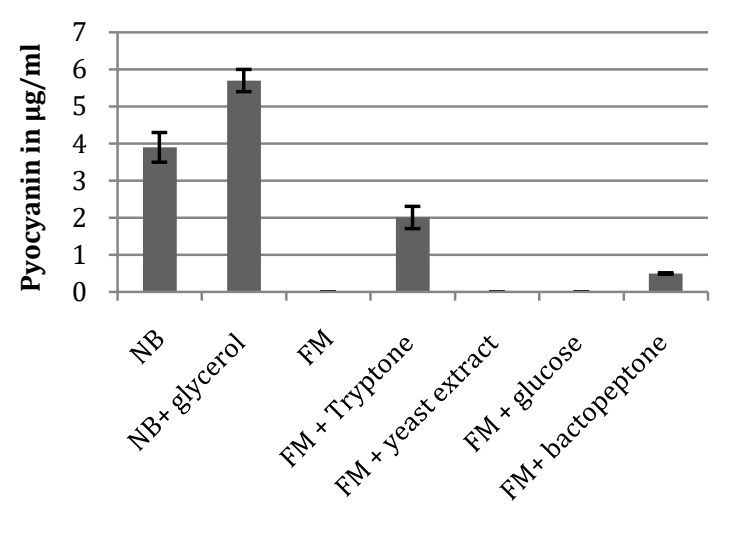

Figure 5a: Effect of medium type on yield of pyocyanin

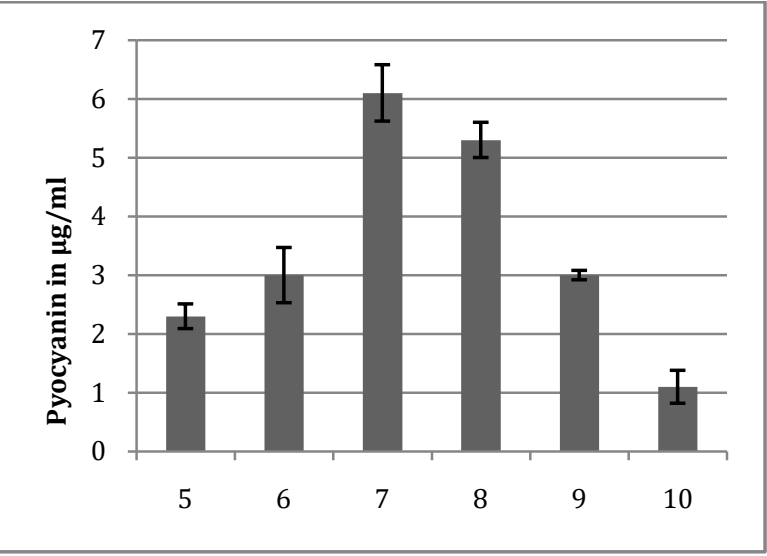

Figure 5c: Effect of $\mathrm{pH}$ on yield of pyocyanin

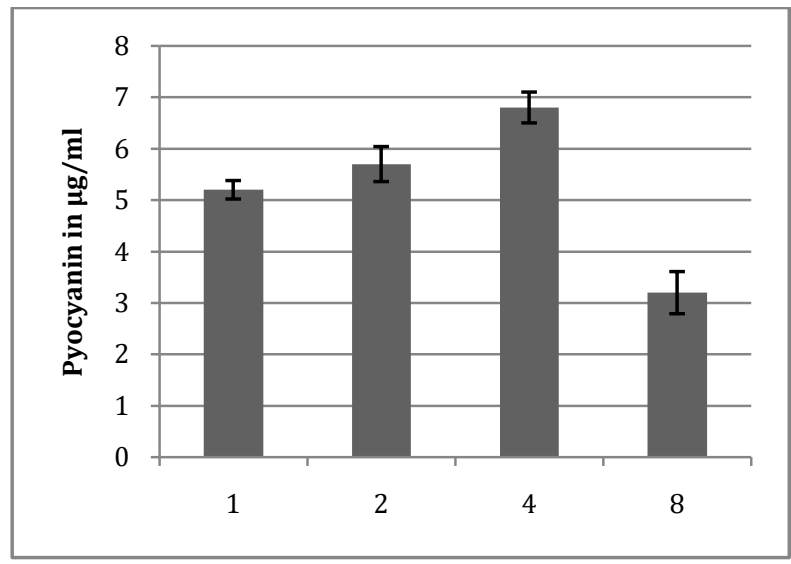

Figure 5e: Effect of salt conc. (\%)on yield of pyocyanin

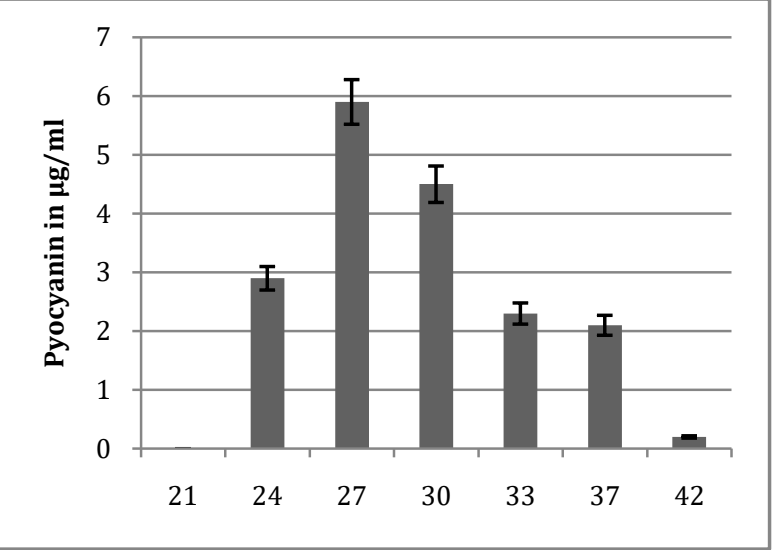

Figure 5b: Effect of temperature of incubation $\left({ }^{\circ} \mathrm{C}\right)$ on yield of pyocyanin

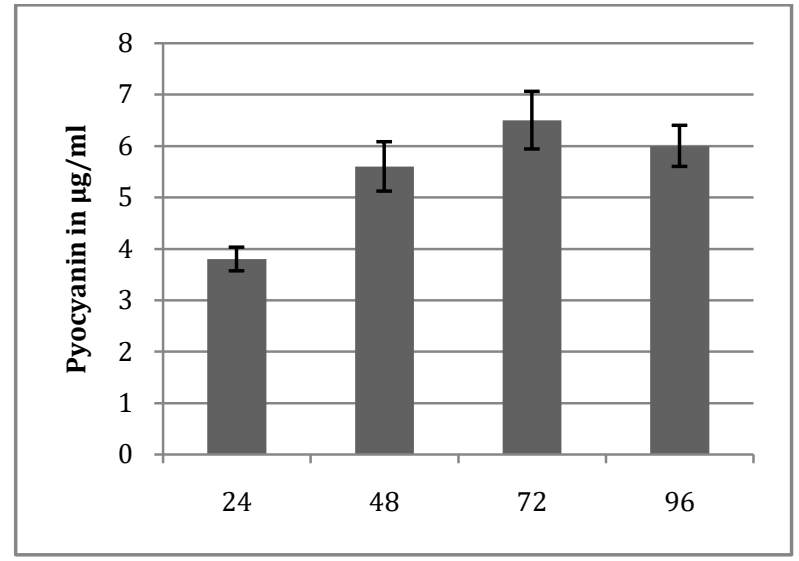

Figure 5d: Effect of time of incubation(hr) on yield of pyocyanin

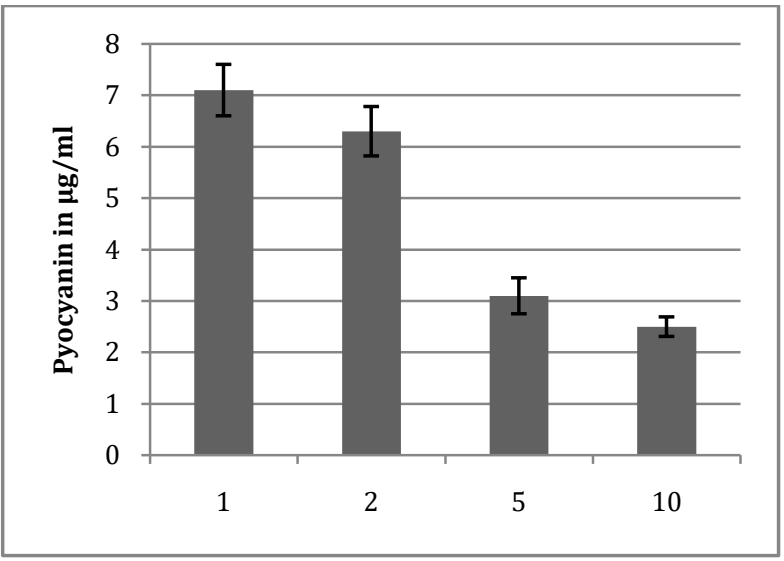

Figure 5f: Effect of inoculum size (\%)on yield of pyocyanin 


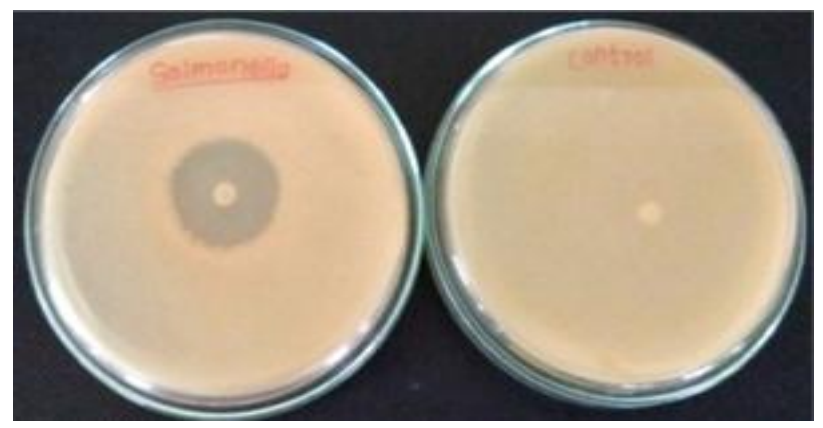

Figure 6.Activity of pyocyanin against Salmonella sp.

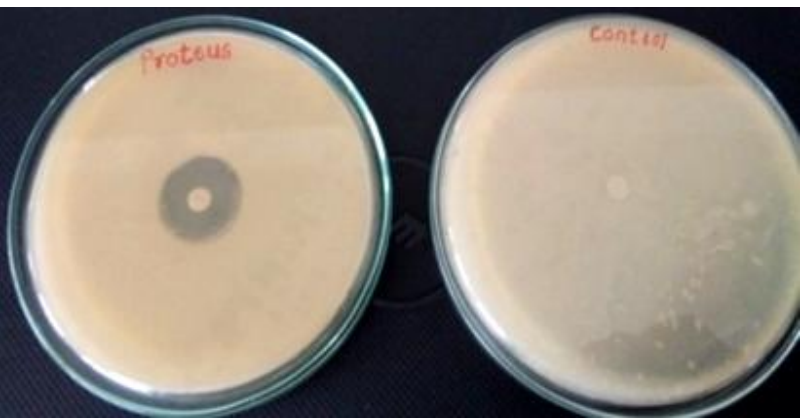

Figure 8.Activity of pyocyanin against Proteus sp.

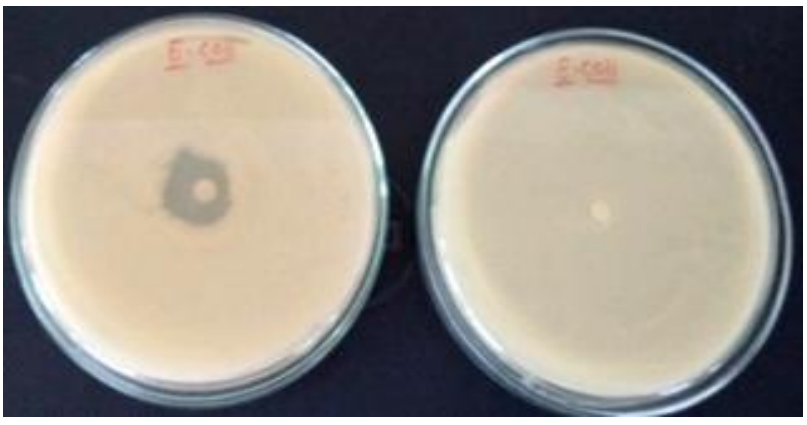

Figure 7.Activity of pyocyanin against Escherichia coli

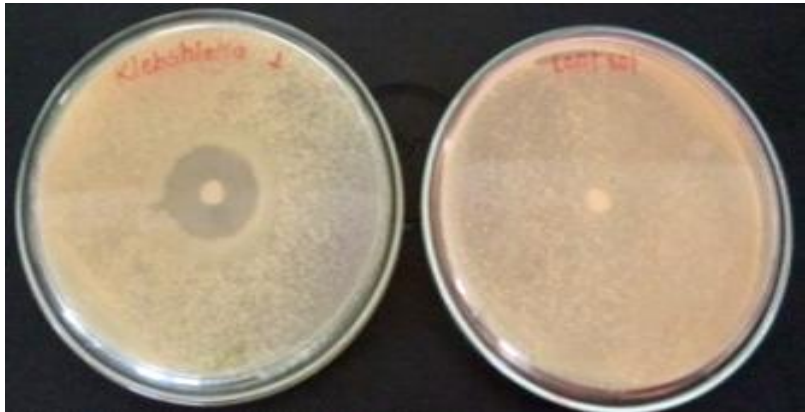

Figure 9.Activity of pyocyanin against Klebsiella sp.

Table 4 MIC of the pyocyanin against selected pathogens

\begin{tabular}{|c|c|c|c|c|c|c|}
\hline \multicolumn{2}{c}{ Pathogens } & Conc. $(\mu \mathrm{gg} / \mathrm{ml})$ & 4 & $\mathbf{8}$ & 12 & -16 \\
\hline Staphylococcus aureus & Growth & + & + & - & - \\
\hline Klebsiella sp. & Growth & + & - & - & - & - \\
\hline
\end{tabular}

\subsection{Minimal Inhibitory Concentration for bacterial pathogens}

Minimum inhibitory concentration was recorded again the two minimum growth showing bacterial pathogens Staphylococcus aureus and Klebsiella sp. No visible growth was observed at concentration 12 and $8 \mu \mathrm{g} / \mathrm{ml}$ for Staphylococcus aureus and Klebsiella sp. Respectively (table 4). Thus MIC of pyocyanin for Staphylococcus aureus and Klebsiella sp. was 12 and $8 \mu \mathrm{g} / \mathrm{ml}$ respectively. Gram negative bacteria Klebsiella sp. than Gram positive Staphylococcus aureus are found to be more sensitive to pyocyanin of $P$. aeruginosa because it act on the cell wall of these bacterial pathogens.
3.8 Antifungal activity of pyocyanin against phytopathogenic fungi

In the present study antifungal activity of pyocyanin was also studied against phytopathogenic fungi Aspergillus niger, Penicillium spp., Rhizopus spp., Trichophyton mentagrophyte, Rhodotorula spp., Alternaria alternate, Trichophyton rubrum and Candida spp. by agar well diffusion method (Figure 10-13). Maximum inhibitory effect of pigment was observed against Aspergillus niger and Penicillium sp., these result are in agreement with the findings of Mahamuni, (2015a), those who reported highest inhibition of Aspergillus niger and Penicillium sp when exposed to pyocyanin. Similarly, Dwivedi \& Johri (2003)

Journal of Experimental Biology and Agricultural Sciences http://www.jebas.org 


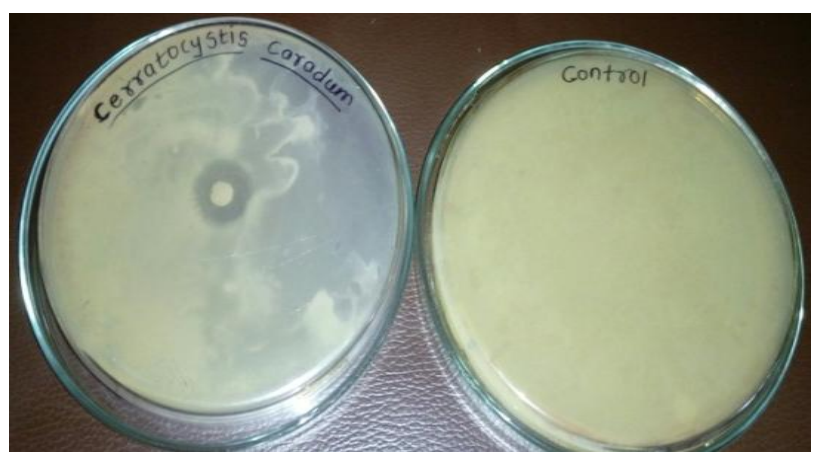

Figure 10 Antagonistic effect on Cerratocystis caradum

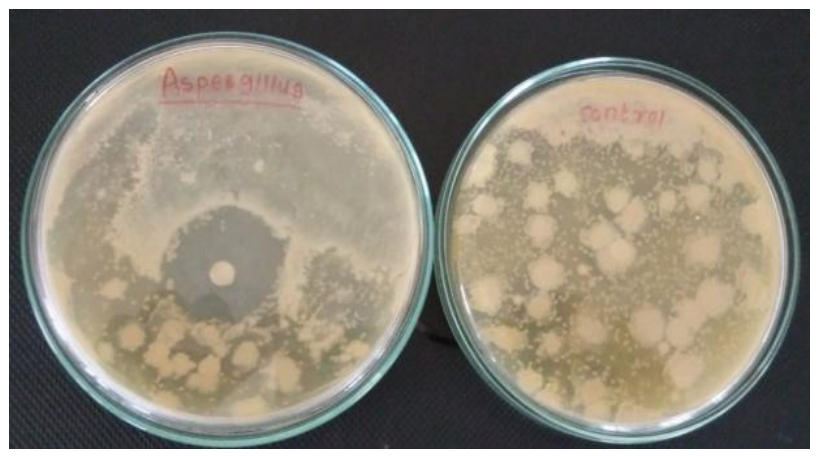

Figure 12 Antagonistic effect on Aspergillus niger

reported that Psuedomonas can suppress soil-borne fungal pathogens by producing antifungal metabolites. Similarly, Hassanein et al. (2009) also reported that pyocyanin produced on King's B medium ( $\mathrm{pH} 7 \pm 0.2)$ and extracted by chloroform showed minimum inhibitory concentration $(40.69 \mu \mathrm{g} / \mathrm{ml})$ against Candida albicans.

\section{Conclusion}

The soil samples collected from Baramati regions showed presence of notable amount of pigment producing bacterial diversity. These bacteria are found to produce wide range of colours including yellow, red, orange, purple etc. Bacterial strain producing blue color pigment pyocyanin was identified morphologically and 16S rDNA technique as P. aeruginosa. This study suggested that morphological and biochemical (API) methods were found effective in identification of bacterial strain and these results can be confirmed by molecular identification techniques 16s rDNA. The selected $P$. aeruginosa JCM 5962(T) found to produce pyocyanin; confirmed by spectroscopic studies. The produced pigment can be successfully purified by gel chromatography techniques. All the parameters for pyocyanin production can be optimized by classical approach. The organism

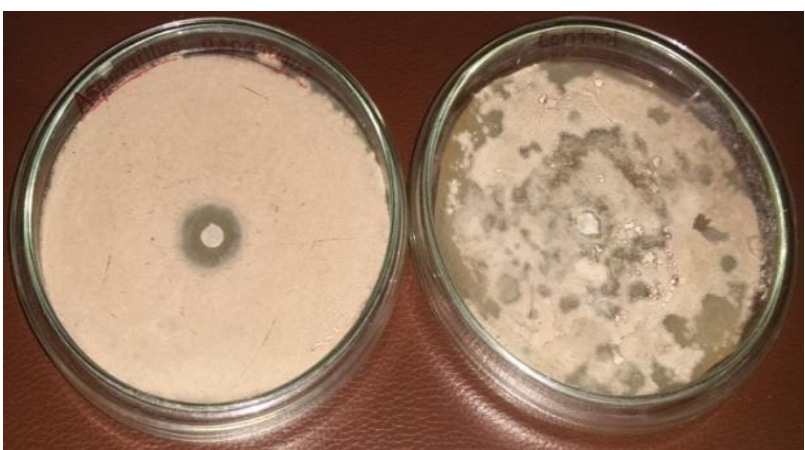

Figure 11 Antagonistic effect on Aspergillus asparagus

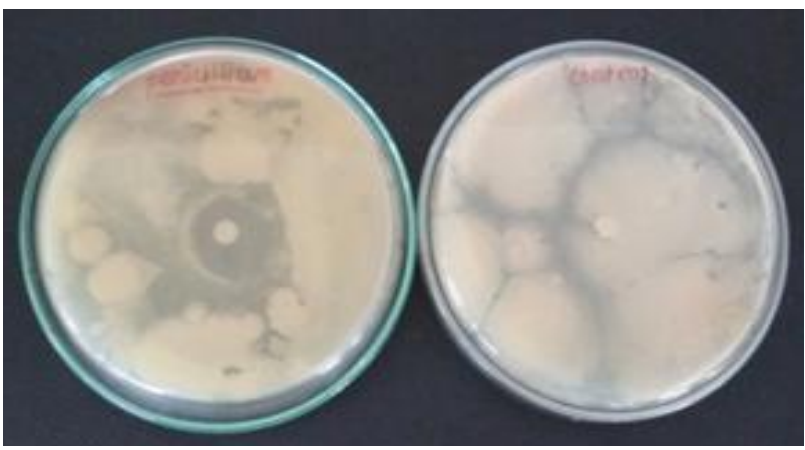

Figure 13 Antagonistic effect on Penicillium sp.

produced maximum pigment at $30^{\circ} \mathrm{C}$, $\mathrm{pH} 7$, salt concentration $4 \%$ after $72 \mathrm{hrs}$ of incubation $120 \mathrm{rpm}$ speed of agitation and $1 \%$ inoculum in $\mathrm{NB}+$ glycerol medium.

As pigment itself having potent antimicrobial activity it takes care of contaminants and minimize the risk of contamination during production process. This finding was confirmed by agar well diffusion assay against Staphylococcus aureus, E. coli, Salmonella sp., Klebsiella sp. and Proteus sp. and found significance in controlling infection caused by these pathogens. This inhibitory effect is due to oxygen reactive species generated by pyocyanin during metabolism.

Broth dilution method was successfully used for determination of MIC for Staphylococcus aureus $(12 \mu \mathrm{g} / \mathrm{ml})$ and Klebsiella sp. $(8 \mu \mathrm{g} / \mathrm{ml})$. Gram negative bacteria are found to be more sensitive to pyocyanin of $P$. aeruginosa as it acts on the cell wall. Phytopathogenic fungi of sugarcane Cerratocystis caradum, Sclerotium sp. and Altenaria alternatum are also found to be sensitive to the pyocyanin produced by the isolated strain which is a novel finding. Other fungi inhibited by pyocyanin are Asporagus sp., Aspergillus niger, Penicillium sp. Thus the pyocyanin produced by Pseudomonas aeruginosa isolated from rhizosphere 
soil showed impressive future prospects in controlling phytopathogenic fungi and for controlling human pathogens.

\section{Conflict of interest}

Author hereby declares that they have no conflict of interest.

\section{References}

Azmana AS, Mawangb CI, Abubakara S (2018) Bacterial Pigments: The Bioactivities and as an Alternative for Therapeutic Applications. Natural Product Communications 13: 1747-1754.

Bhatini VP, Francis S, Jayaraman A, Mithusamy P (2013) Optimization and production of prodigiosin from Serrtia marcescens MBB05 using various natural substrates. Asian Journal of Pharmaceutical and Clinical Research 6:34-41.

Bodey GP, Bolivar R, Fainstein V, Jadeja L (1983) Infections caused by Pseudomonas aeruginosa. Reviews of infectious diseases 5: 279-313.

Cheluvappa R, Shimmon R, Dawson M, Hilmer S, David G, Couteur L (2008) Reaction of Pseudomonas aeuroginosa pyocynin with reduced glutathione. Acta Biochimica Polonica 55: 571-580.

Dwivedi D, Johri B (2003). Antifungals from fluroscent pseudomonas biosynthesis and regulation. Current Science 85: 1693-1703.

El-Fouly M, Sharaf A, Shahin A, Heba A, El-Bialya A, Omara MA (2015) Biosynthesis of pyocyanin pigment by Pseudomonas aeruginosa. Journal of Radiation Research and Applied Sciences 8: 36-48.

Essar DW, Eberly L, Hadero A, Crawford P (1990) Identification and characterization of genes for a second anthranilate synthase in Pseudomonas aeruginosa: interchangeability of the two anthranilate synthases and evolutionary implications. Journal of Bacteriology 172: 884-900.

Girard G, Bloemberg GV (2008) Central role of quorum sensing in regulating the production of pathogenicity factors in Pseudomonas aeruginosa. Future Microbiology 3: 97-106.

Hassanein W, Awny N, EI- Mougith A, Salah EI-Dien S (2009) The antagonistic activities of some metabolites produced by Pseudomonas aeruginosa sha8. Journal of Applied Sciences Research 5: 404-414.

Hassani HH, Hasan HM, Al-Saadi A, Ali AM, Muhammad MH (2012) A comparative study on cytotoxicity and apoptotic activity of pyocyanin produced by wild type and mutant strains of Pseudomonas aeruginosa. European Journal of Experimental Biology 2: 1389-1394.

Igbinosa IH, Igbinosa EO (2015) The Pseudomonads as a versatile opportunistic pathogen in the environment. In: MéndezVilas A (Ed.) The Battle Against Microbial Pathogens: Basic Science, Technological Advances and Educational Programs, Formatex Research Center Publication.

Jameel ZJ, Hussain AF, Al-Mahdawi MA, Nuha FA, Alkerim NF,Alrahman ES (2017) Bioactivity of pyocyanin of Pseudomonas aeruginosa clinical isolates against a variety of human pathogenic bacteria and fungi species. The International Arabic Journal of Antimicrobial Agents7: 1-7.

Jayaseelan S, Ramaswamy D, Dharmaraj S (2014) Pyocyanin: production, applications, challenges and new insights. World Journal of Microbiology and Biotechnology 30:1159-1168

Kim SW, Jung JH, Lamsal K, Kim YS, Min JS, Lee YS (2012) Antifungal effect of Silver nanoparticles (AgNPs) against various plant pathogenic fungi. Mycobiology 40: 53-58.

Mahamuni SV (2015a) Antifungal Properties of Burkholderia cenocepacia Strain VIMP 01 (JQ867371) against Ceratocystis paradoxa and Alternaria alternate. International Journal of Bioassays 4: 4290-4295.

Mahamuni SV (2015b) Antifungal Trait of Burkholderia gladioli Strain VIMP 02 (JQ811557). International Journal of Science and Research 4: 2059-2064.

Maleki M, Mostafaee S, Mokhtarnejad L, Farzaneh M (2010) Characterization of Pseudomonas fluorescens strain CV6 isolated from cucumber rhizosphere in varami as a potential biocontrol agent. Australian Journal of Crop Science 4: 676-683.

Mamunur R, Fakruddin R, Mohammad M, Fatema K, Alimuddin C (2014) Anti-Bacterial Activity of Pigments Isolated From Pigment-Forming Soil Bacteria. British Journal of Pharmaceutical Research 4: 880-894.

Marathe RJ, Phatake YB, Sonawane AM (2015) Bio-prospecting of Pseudomonas aeruginosa for their potential to produce siderophore, process optimization and evaluation of its bioactivity. International Journal of Bioassays 4: 3667-3675.

Mavrodi DV, Bonsall RF, Delaney SM, Soule MJ, Phillips G, Thomashow LS (2001) Functional analysis of genes for biosynthesis of pyocyanin and phenazine-1-carboxamide from Pseudomonas aeruginosa PA01. Journal of bacteriology 183: 6454-6465.

Mesquita C, Pedro M, Santos L (2013) Pseudomonas aeruginosa: phenotypic flexibility and antimicrobial resistance. In: Méndez- 
Vilas A (Ed.) Microbial pathogens and strategies for combating them: science, technology and education, Formatex Research Center Publication Pp.650-665

Mitra R, Vakilwala J (2015) Microbial response of natural pigment pyocyanin isolated from Pseudomonas aeruginosa. $2^{\text {nd }}$ International Conference on Multidisciplinary Research \& Practice 3: 232-235.

Mohammed TA, Almahde MAM (2017) Antimicrobial Activity of Pyocyanin for Inhibition of Pseudomonas aeruginosa Urinary Tract Pathogens. Asian Journal of Medicine and Health 4: 1-9. 10.9734/AJMAH/2017/33379.

Ohfuji K, Sato N, Hamada-Sato N, Kobayashi T, Imada C, Okuma H, Watanabe E (2004) Construction of glucose sensor based on a screen-printed electrode and a novel mediator pyocyanin from Pseudomonas aeruginosa. Biosensor and Bioelectronics 19: 1237-1244.

Ozcan D, Kaharaman H (2015) Pyocynin production in the presence of calcium ion in Pseudomonas aeruginosa and recombinant bacteria. Turkish Journal of Science and Technology 10: 13-19.

Palanichamy V, Hundet A, Mitra B, Reddy N (2011) Optimization of cultivation parameters for growth and growth and pigment production by Streptomyces spp. isolated from marine sediment and rhizosphere soil. International Journal of Plant, Animal and Environmental Sciences 1: 2231-4490.

Pedro PL, Chioma WQ (2018) Antibiotic susceptibility of resistant Pseudomonas species generated through the use of differential and selective media for isolation of Pseudomonas from environmental samples. South Asian Journal of Research in Microbiology 2: 1-9.

Perneel M, Heyraman J, Adiobo1 A, De Maeyer K, Raaijmakers J, Vos P, Hofte M (2007) Characterization of CMR5c and CMR12a, novel flurescent Pseudomonas strains from the cocoyam rhizosphere with biocontrol activity. Journal of Applied Microbiology 103:1007-20.

Phatake YB, Dharmadhikari SM (2016) Physical parameter optimization for enhancement of prodigiosin production by using Serratia spp. World journal of Pharmaceutical and Medical research 2: 40-48.

Ponce OJ, Spencer-Bonilla G, Alvarez-Villalobos N, Serrano V, Singh-Ospina N, Rodriguez-Gutierrez R, Salcido-Montenegro A, Benkhadra R, Prokop LJ, Bhasin S, Brito JP (2018) The efficacy and adverse events of testosterone replacement therapy in hypogonadal men: A systematic review and meta-analysis of randomized, placebo-controlled trials. The Journal of Clinical
Endocrinology \& Metabolism 103: 1745-1754. DOI https://doi.org/10.1210/jc.2018-00404.

Rao MPN, Xiao M, Li WJ (2017) Fungal and bacterial pigment: Secondary metabolite with wide applications. Frontiers in Microbiology 8: 1-13.

Stover CK, Pham XQ, Erwin AL, Mizoguchi SD, Warrener P, Hickey MJ, Brinkman FS, Hufnagle WO, Kowalik DJ, Lagrou M, Garber RL, Goltry L, Tolentino E, Westbrock-Wadman S, Yuan Y, Brody LL, Coulter SN, Folger KR, Kas A, Larbig K, Lim R, Smith K, Spencer D, Wong GK, Wu Z, Paulsen IT, Reizer J, Saier MH, Hancock RE, Lory S, Olson MV (2000) Complete genome sequence of Pseudomonas aeruginosa PAO1, an opportunistic pathogen. Nature 406: 959-64.

Sudhakar T, Karpagam S, Sabapathy S (2013) Analysis of pyocyanin compound and its antagonistic activity against phytopathogens. International Journal of Chemical Technology Research 5: 1101-1106.

Usman HM, Abdulkadir N, Gani M, Maiturare HM (2017) Bacterial pigments and its significance. MOJ Bioequivalence and Bioavailability 4: 285-288.

Venil C, Zakaria Z, Wan A (2013) Bacterial pigment and their applications. Process Biochemistry 48: 1065-1079.

Vipin C, Ashwini P, Kavya AV, Rekha PD (2017) Overproduction of pyocyanin in Pseudomonas aeruginosa by supplementation of pathway precursor shikimic acid and evaluation of its activity. Research Journal of Pharmacy and Technology 10: 533-536.

Vora J, Jain N, Modi H (2014) Extraction, Characterization and Application studies of red pigment of Halophile Serratia marcescens KH1R KM035849 isolated from Kharaghoda soil. International Journal of Pure and Applied Bioscience 2: 160-168.

Weose CR (1987) Bacterial evolution. Microbiological reviews $51: 221-271$.

Zahraa JJ, Anaam FH, Muthana A, Al-Mahdawi, Nuha F, Abed A, Eman SA (2017) Bioactivity of pyocyanin of Pseudomonas aeruginosa clinical isolates against a variety of human pathogenic bacteria and fungi species. The International Onal Arabic Journal of Anti microbial Agents 7:1-7.

Zhao J, Wu Y, Alfred AT, Wei P, Yang S (2014) Anticancer effects of pyocyanin on HepG2 human hepatoma cells. Letters of Applied Microbiology 58: 541-548.

Pachori P, Gothalwal R, Gandhi P (2019) Emergence of antibiotic resistance Pseudomonas aeruginosa in intensive care unit; a critical review. Genes and Diseases 6: 109-119. 